\title{
New distributional, biological and taxonomic information on the genus Eulophinusia Girault (Hymenoptera: Eulophidae)
}

\author{
CHRISTER HANSSON ${ }^{1}$, WINNIE HALLWACHS ${ }^{2,3}$ \& DANIEL H. JANZEN ${ }^{2,4}$ \\ ${ }^{1}$ Scientific Associate Biological Museum (Entomology), Lund University, Sölvegatan 37, SE-22362 Lund, Sweden \& the Natural His- \\ tory Museum, Life Sciences, Cromwell Road, London SW7 5BD, United Kingdom. \\ ఏ"Christer.Hansson@biol.lu.se; 으thtps://orcid.org/0000-0002-9429-0197 \\ ${ }^{2}$ Department of Biology, 433 South University Avenue, University of Pennsylvania, Philadelphia, PA 19104, USA. \\ 3 ["whallwac@sas.upenn.edu; @ i https://orcid.org/0000-0002-5166-809X \\ 4”=djanzen@sas.upenn.edu; @i https://orcid.org/0000-0002-7335-5107
}

\begin{abstract}
The genus Eulophinusia Girault (Hymenoptera: Eulophidae), previously known from Australia and India, is newly recorded from the Americas (Canada, Costa Rica, Dominican Republic). The morphological diagnosis of the genus is enhanced through the discovery of an unnoticed and unique feature - an intricate jigsaw-like microsculptural pattern on the mesoscutellum. The new species described here, Eulophinusia andreamezae Hansson, is a hyperparasitoid. The majority of the Costa Rican specimens of this species were reared from pupae of Hypomicrogaster largus Valerio (Braconidae: Microgastrinae) that had parasitized a caterpillar of Anadasmus Janzen11 (Lepidoptera: Depressariidae) feeding on Ocotea insularis (Lauraceae).
\end{abstract}

Key words: new species, Nearctic, Neotropical, morphological diagnosis, DNA barcode, microsculpture, Hypomicrogaster largus, hyperparasitoid, Anadasmus, Depressariidae

\section{Introduction}

The genus Eulophinusia is a small Eulophinae group comprising 19 species hitherto found mainly in Australia (Bouček 1988). Bouček listed 17 Australian species but stated that several of them were probable synonyms of $E$. cydippe Girault, the type species of the genus; he also synonymized four genera under Eulophinusia. All five genera, including Eulophinusia, were described by Girault. In addition two species are recorded from India by Narendran, (2011). who also synonymized two genus names under Eulophinusia.

Both Bouček (1988) and Narendran (2011) regarded Eulophinusia as closest to the cosmopolitan genus Sympiesis Förster on the basis of unspecified similarities. Bouček also compared Eulophinusia to Paraolinx Ashmead, an exclusively American genus, with which Eulophinusia shared the features small size, short and stout antennae in both sexes, and cross-striped frons.

\section{Morphological terms, abbreviations and acronyms}

Morphological terms follow Gibson (1997) except for mesoscutellum, which is used instead of "scutellum". Abbreviations: $\mathrm{F} 1-\mathrm{F} 4=$ funiculars $1-4 ; \mathrm{Gt}_{7}=$ gastral tergite 7 . For illustrations of the morphological terms see Gibson (1997) and www.neotropicaleulophidae.com.

The following acronyms are used to designate the museums in which types of the new species are deposited: ANIC = Australian National Insect Collection, Canberra, Australia; $\mathrm{CNC}=$ Canadian National Collection of Insects, Ottawa, Canada; MZLU = Entomological collections, Biological Museum, Lund University, Lund, Sweden; MZUCR = Museo de Zoología, Universidad de Costa Rica, San José, Costa Rica; NHMUK = the Natural History Museum, London, United Kingdom. 
The name "Anadasmus Janzen11" is an interim name for an undescribed species in genus Anadasmus. The use of such interim names is explained in Fleming et al. (2019).

The ratios in the description are based on the female holotype and one of the male paratypes. These two type specimens are slightly shriveled but non-collapsed, accurate measurements can thus be taken.

The SRNP code associated with the holotype of E. andreamezae (09- SRNP-1545) is actually the code for the caterpillar host, while the DHJPAR code (DHJPAR0035556) is the code for the holotype itself.

\section{Imaging}

The colour images of the specimens were made using Canon camera equipment, including an EOS 5D Mark IV body, a telezoom lens, 70-300 $\mathrm{mm}$ (but using only $200 \mathrm{~mm}$ ), with a $10 \times$ Mitutoyo microscope lens attached, and macro twin lite MT-24 EX for illumination. The camera was attached to a Cognisys stackshot macrorail system. The picture stacking was done with Helicon Focus version 6, and Adobe Photoshop was used for image processing. The SEM micrographs are from uncoated specimens and were done with a $\mathrm{JEOL}^{\circ} \mathrm{JSM} 5600 \mathrm{LV}$ scanning microscope, in low vacuum and using a backscatter detector.

\section{Eulophinusia Girault}

Eulophinusia Girault, 1913a: 457. Type species: Eulophinusia cydippe Girault, by original designation and monotypy.

Alophomopsis Girault, 1913b: 281-282. Type species: Alophomopsis spenceri Girault, by original designation and monotypy. Synonymized by Bouček (1988: 624).

Grotiusella Girault, 1913b: 283. Type species: Grotiusella fasciatifrons Girault, by original designation and monotypy. Synonymized by Bouček (1988: 624). Eulophinusia was synonymised under Grotiusella by Girault (1915: 288), but Eulophinusia has priority over Grotiusella (Bouček 1988: 624).

Elachertonecremnus Girault, 1913b: 293. Type species: Elachertonecremnus circumjectus Girault, by monotypy. Synonymized by Bouček (1988: 624).

Babinda Girault, 1922: 100. Type species: Babinda murarriensis Girault, by monotypy. Synonymized by Bouček (1988: 624).

Arunus Jaikishan Singh and Khan, 1997: 9. Type species: Arunus indicus Jaikishan Singh \& Khan, by original designation and monotypy. Synonymized by Narendran (2011:182-183).

Pradeshia Koçak and Kemal, 2008: 7. Replacement name for Arunus Jaikishan Singh \& Khan, 1997. Synonymized by Narendran (2011:182-183).

Diagnosis. Sculpture on mesoscutellum intricate and even jigsaw-like (Figs 7, 9) - not as reticulation, which is the usual mesoscutellar sculpture in the Eulophidae; axillae strongly advanced forwards so that at least $2 / 3$ are in front of anterior margin of mesoscutellum (Figs 6, 8); flagellum in both sexes short and stout with transverse flagellomeres (Figs 3, 4); head with transverse yellow markings on frons (Fig. 5); postmarginal vein short, about as long as stigmal vein (Fig. 1); males with unbranched antennae (Fig. 4); small size (1.1-1.4 mm).

Distribution. Australia (Bouček 1988), India (Narendran 2011), and newly recorded here: Canada, Costa Rica, and the Dominican Republic.

Biology. Bouček (1988) mentions Australian species reared as parasitoids of small moths: unidentified species of Tortricidae, "cotton webworm", and gregarious parasitoids on the soybean moth (Aproaerema simplexella) (Gelechiidae); specimens of the Indian species Eulophinusia indica were reared from leaf galls of Trioza fletcheri Crawford (Hemiptera: Triozidae) (Jaikishan Singh \& Khan 1997). While there is just one rearing of the species described here, it is clearly a hyperparasitoid of a gregarious microgastrine small braconid wasp, Hypomicrogaster largus Valerio, that had parasitized a small leaf-rolling depressariid moth (Anadasmus Janzen11).

\section{Eulophinusia andreamezae Hansson, sp. nov.}

Figures 1-7, 10

Diagnosis. Differs from E. cydippe (the type species of Eulophinusia) in the setation and sculpture on midlobe of mesoscutum: with numerous scattered setae and with the socket of each seta surrounded by a large ring (Fig. 6); E. cydippe has its setae in two rows and sockets lack rings (Fig. 8). 


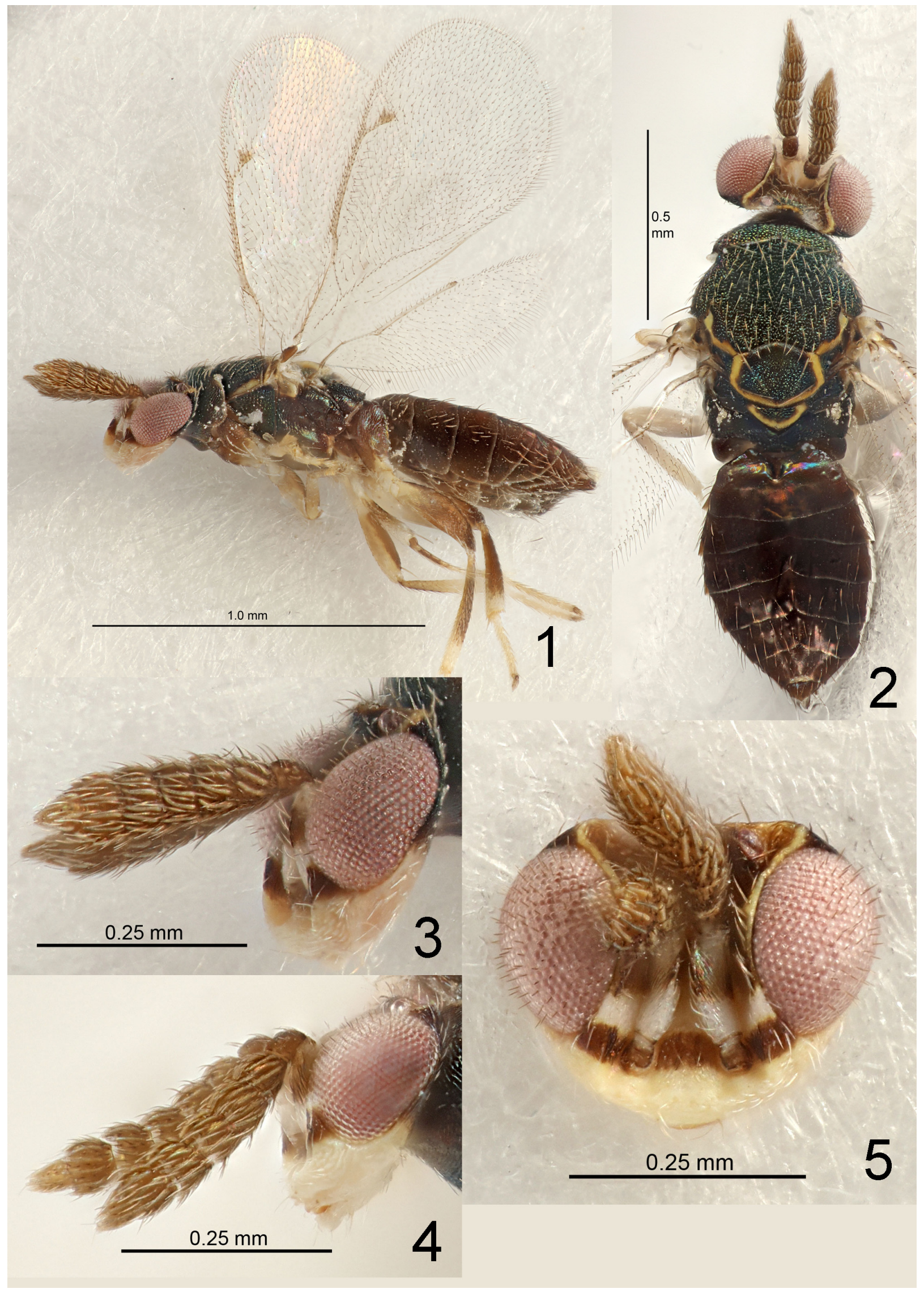

FIGURES 1-5. Eulophinusia andreamezae Hansson sp. nov., paratypes; 1 body in lateral view, female; 2, body in dorsal view, female; $\mathbf{3}$, head+antennae in lateral view, female; $\mathbf{4}$, head+antennae in lateral view, male; 5 , head in frontal view, female. 


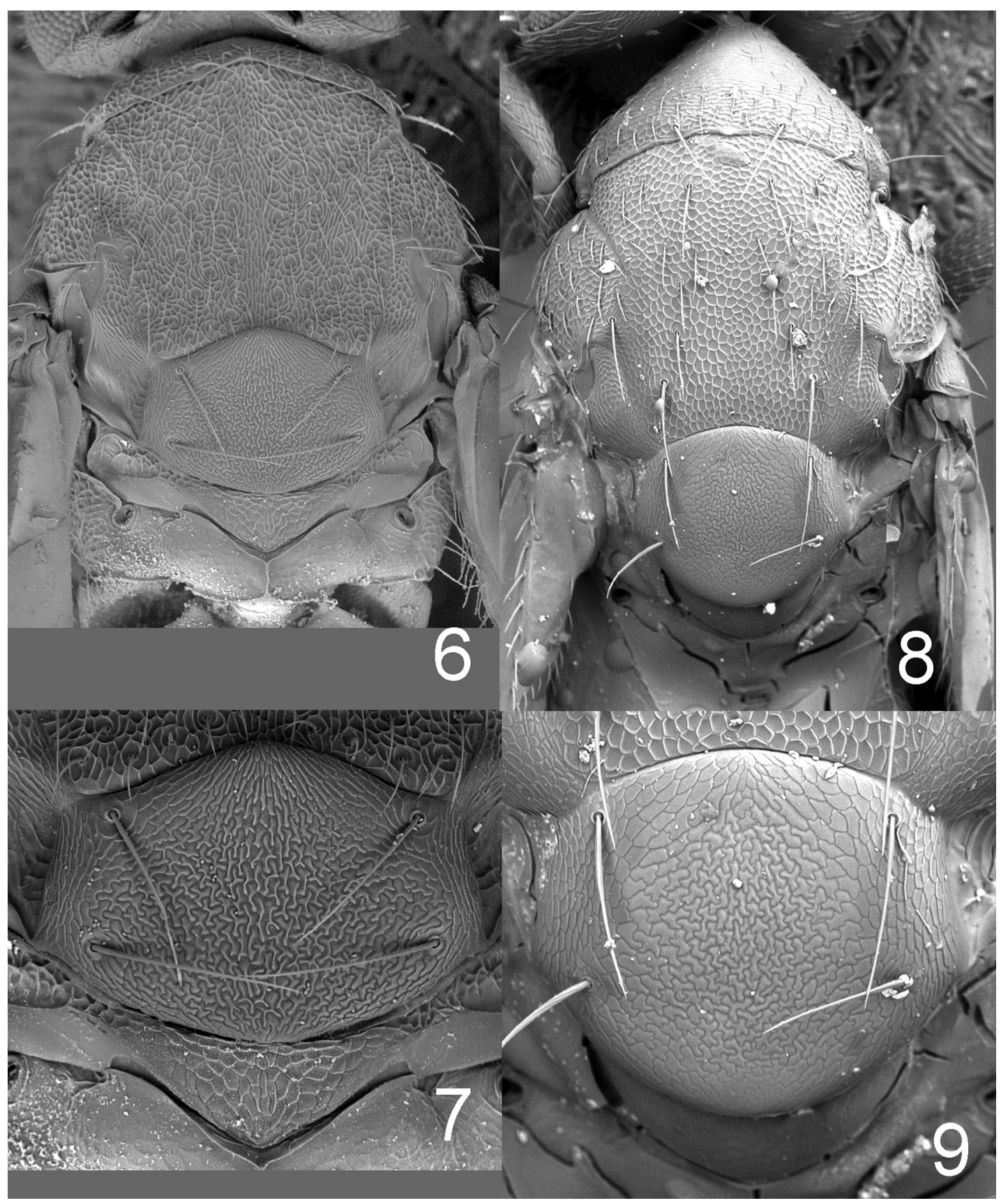

FIGURES 6-9. Eulophinusia spp., females; 6-7, E. andreamezae Hansson sp. nov., holotype (DHJPAR0035556); 6, thoracic dorsum; 7, meso-scutellum in dorsal view; 8-9, E. cydippe Girault, non-type; 8, thoracic dorsum; 9, mesoscutellum in dorsal view.

Description (female holotype). Length of body $1.4 \mathrm{~mm}$ (paratypes 1.1-1.4 mm). Antenna (Fig. 3) with scape white with a dark brown spot medially, pedicel and flagellum dark brown; flagellum stout with transverse flagellomeres, funicle 4-segmented and clava 2-segmented. Frons below frontal suture yellowish-white with two transverse dark brown bands, one level with antennal toruli and one just below frontal suture (Fig. 5); with strong reticulation, smooth just below frontal suture. Vertex metallic bluish-green inside ocellar triangle, brown outside ocellar triangle, with strong reticulation. Occipital margin rounded.

Mesoscutum metallic bluish-green (Fig. 2); with numerous scattered setae and with the socket of each seta surrounded by a raised ring (Fig. 6); notauli indicated by a groove in anterior 1/3 (Fig. 6); with strong reticulation. Mesoscutellum metallic bluish-green with lateral and posterior margins yellowish-white (Fig. 2); flattened (Figs 6, 7 ), $0.7 \times$ as long as wide, with sculpture similar to a jigsaw puzzle (Fig. 7); without sublateral grooves or pit-rows; with two pairs of setae attached laterally. Axillae (Fig. 2) metallic bluish-green with a yellowish-white band medi- 
ally; strongly advanced forwards and with strong reticulation (Fig. 6). Dorsellum (Fig. 2) metallic bluish-green with posterior margin yellowish-white; triangular with weak reticulation and slightly convex, $1.0 \times$ as long as length of median propodeum. Propodeum (Fig. 2) metallic bluish-green, with parts between spiracles with very weak reticulation and propodeal callus with strong reticulation (Fig. 6), with a carina that follows posterior margin of dorsellum and with a complete median carina; propodeal callus with five setae. Legs (Fig. 1) with coxae dark brown with metallic tinges; fore and mid femora white with ventral margin dark brown, hind femur dark brown with base white; fore and mid tibia white, hind tibia dark brown with apical $1 / 4$ white; tarsi white. Wings (Fig. 1) hyaline, veins yellowish-brown and setae dark brown; fore wing with submarginal vein with seven setae on dorsal surface; speculum very small and closed posteriorly, separated from cubital line by several rows of setae; costal cell with a complete row of setae on ventral surface, and margin with eight setae in apical $1 / 3$; basal cell bare; hind wing with apex rounded.

Petiole black and shiny, very short and transverse. Gaster (Fig. 2) ovate, metallic purple, and smooth.

Ratios. Head: width/length (dorsal view) 2.33; width/length (frontal view) 1.35; shortest distance between posterior ocelli/ocelli and eyes 1.75; shortest distance between posterior ocelli /posterior ocellus width 2.33; head width/mesosoma width 0.97 ; mouth width/malar space 1.50 ; malar space/eye height 0.50 ; scape length/eye height 0.63; flagellum+pedicel length/mesosoma width 0.76; scape length/width 2.50; F1 length/width 0.90; F2 length/ width $0.58 ; \mathrm{F} 3$ length/width 0.58 ; F4 length/width 0.58 ; clava length/width 1.33 ; clava width/F1 width 1.20 ; pedicel length/F1 length $0.78 ; \mathrm{F} 1$ width/pedicel width 1.43. Mesosoma: length/width 1.36; midlobe of mesoscutum length/ mesoscutellum length 1.85 ; dorsellum length/propodeum length 1.0 ; mesoscutellum length/width 0.69 ; fore wing length/width 2.0; costal cell length/width 10.0; costal cell length/marginal vein length 1.20; marginal vein length/ stigmal vein length 3.33; postmarginal vein length/stigmal vein length 0.87. Metasoma: gaster length/width 1.57; gaster length/mesosoma length $1.12 ; \mathrm{Gt}_{7}$ length/width 0.40 .

Male. Length of body $1.1 \mathrm{~mm}$. Similar to female except a shorter gaster (length gaster/mesosoma $=1.1$ ), and with a large white spot in anterior $1 / 2$.

Ratios. Head: width/length (dorsal view) 2.41; width/length (frontal view) 1.26; shortest distance between posterior ocelli/ocelli and eyes 3.50; head width/mesosoma width 1.02; mouth width/malar space 2.10; malar space/eye height 0.38 ; scape length/eye height 0.73 ; flagellum+pedicel length/mesosoma width 0.96 ; scape length/width 2.71 ; F1 length/width 1.0; F2 length/width 0.88; F3 length/width 0.88; F4 length/width 0.78; clava length/width 1.67; clava width/F1 width 1.29. Mesosoma: length/width 1.35. Metasoma: gaster length/width 1.65; gaster length/mesosoma length 1.09 .

Variation. Apart from some variation in size there is little variation in the material.

Hosts and biology. Hyperparasitoid on gregarious Hypomicrogaster largus Valerio (Braconidae: Microgastrinae) parasitizing caterpillar of Anadasmus Janzen11 (Lepidoptera: Depressariidae) feeding on Ocotea insularis (Lauraceae). The eulophid parasitoids emerged from the microgastrine cocoons attached to the leaf close to the lepidopteran host (Fig. 10). Twenty-three females and two males of $E$. andreamezae emerged from one reared wildcaught caterpillar from ACG (Área de Conservación Guanacaste) rain forest.

Distribution. Canada, Costa Rica (Alajuela, Heredia \& Puntarenas Provinces), Dominican Republic. DNA barcoding may possibly reveal a complex of sibling species, as being found to be the case with many other ACG parasitic small wasps (e.g. Smith et al. 2008).

Etymology. Named in honor of Ministra Andrea Meza Murillo of the Ministerio de Recursos Naturales y Energía de Costa Rica in recognition of her taking on this difficult ministerial task mid-government, and for being sympathetic to the peculiar needs of Área de Conservación Guanacaste for its survival.

Material. Holotype female labelled "COSTA RICA, Alajuela, ACG, Sector San Cristobal, Puente Palma, 460m, 32¹9’05”N 38 55'10”'E, 21.iv.2009, G. Sihezar", "Ex Anadasmus sp. on Ocotea insularis", "Voucher: D.H. Janzen \& W. Hallwachs, DB: http://janzen,sas,upenn.edu, Area de Conservacion Guanacaste, COSTA RICA, 09SRNP-1545, DHJPAR0035556" in MZLU. Paratypes (27우 20): 22 우 $20^{\Uparrow}$ with same label data as holotype (CNC, MZLU, MIUCR, NHMUK); 1 q “ONT, Almonte, I.1968, MT, Denis Dumouchel” [=CANADA, Ontario] (ANIC); 1 ㅇ “COSTA RICA, Heredia, Estación Biológica La Selva, 100-200m, LN264463/532850, 30-31.iii.2002, swept, J. Azofeifa” (NHMUK); 1 ' “COSTA RICA, Puntarenas, Estación Altamira, Sendero Los Gigantes, 1450m, 902'N 8300'W, 7.ii-5.iii.2002, swept, C. Hansson \& Parataxonomos" (MZLU); 1 \% “COSTA RICA, Puntarenas, Parque Nacional Corcovado, Estación Los Patos, $08^{\circ} 33^{\prime} \mathrm{N}$ 8330’W, 200m, ii.2000, J.S. Noyes” (NHMUK); 1 \% “DOMINICAN REPUBLIC, Barahona, Sierra de Bahoruca, Alcoa Road Km 25, 18.i.1989, L. Masner" (ANIC). 


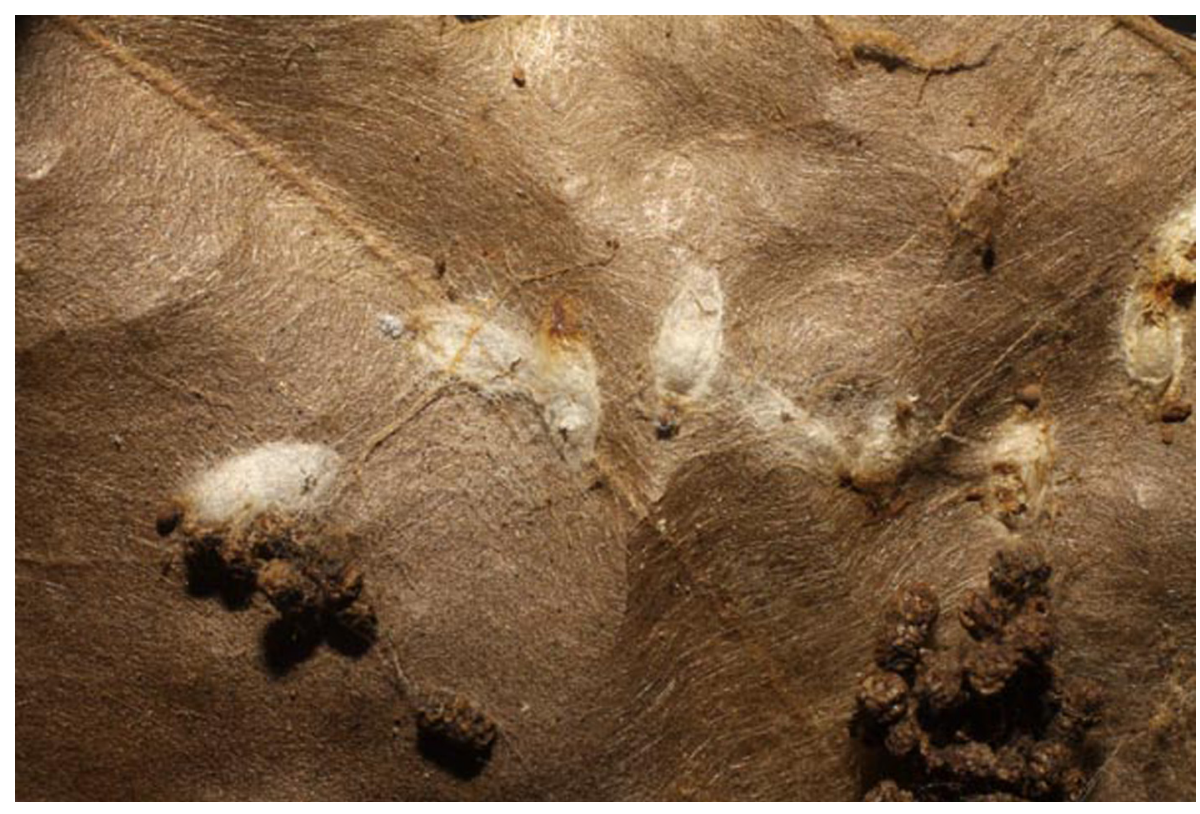

FIGURE 10. Cocoons of Hypomicrogaster largus Valerio with exit holes from Eulophinusia andreamezae Hansson sp.nov. The unique code for this image is 09-SRNP-1545-DHJ474859.jpg.

\section{Discussion}

Species of Eulophinusia are easily identified through the peculiar microsculpture on mesoscutellum, which is a unique feature for this genus. Habitually Eulophinusia is most similar to Paraolinx, but can be separated from this genus through the lack of notaular grooves, which are deep and complete in Paraolinx. However, species of Eulophinusia and Sympiesis do not appear especially similar. Even though Eulophinusia shares certain features with Sympiesis: scape not reaching above level of vertex, lack of notaular grooves on mesoscutum, mesoscutellum without longitudinal grooves and with two pairs of setae, these features are not unique to these two genera. The small size, the short and stout antennae in both sexes, the cross-striped frons, and the short postmarginal vein in the fore wing are some of the features that separate Eulophinusia from Sympiesis. It is thus difficult to hypothesize phylogenetic relationships with other Eulophinae genera based on morphological data alone; future molecular data are necessary for such hypotheses.

\section{Acknowledgements}

Thank you to John S. Noyes (NHMUK) and John LaSalle (ANIC) for loan of specimens. John LaSalle sadly passed away before this publication, but he generously shared specimens for this study. Gerard Delvare, an anonymous reviewer and Natalie Dale-Skey are acknowledged for valuable comments on the manuscript. The Microscopy Facility at the Department of Biology, Lund University is acknowledged for the use of their scanning electron microscope. We thank the parataxonomist team of Área de Conservación Guanacaste (Janzen and Hallwachs 2011) for finding and rearing the host caterpillar and its parasitoids and hyperparasitoids.

\section{References}

Bouček, Z. (1988) Australasian Chalcidoidea (Hymenoptera). A biosystematic revision of genera of fourteen families, with a reclassification of species. CAB International, Wallingford, Oxon and Cambrian News Ltd., Aberystwyth, Wales, 832 pp.

Fleming, A., Wood, D., Smith, M., Dapkey, T., Hallwachs, W. \& Janzen, D. (2019) Twenty-two new species in the genus Hyphantrophaga Townsend (Diptera: Tachinidae) from Area de Conservación Guanacaste, with a key to the species of Mesoamerica. Biodiversity Data Journal, 7, e29553. 
https://doi.org/10.3897/BDJ.7.e29553

Gibson, G.A.P. (1997) Morphology and terminology. In: Gibson, G.A.P., Huber, J.T. \& Woolley, J.B. (Eds.), Annotated keys to the genera of Nearctic Chalcidoidea (Hymenoptera). NRC Research Press, Ottawa, pp. 16-44.

Girault, A.A. (1913a) Three new genera of chalcidoid Hymenoptera from Queensland. Entomological News, 24, 457-460.

Girault, A.A. (1913b) Australian Hymenoptera Chalcidoidea IV. Memoirs of the Queensland Museum, 2, 140-296. https://doi.org/10.5962/bhl.title.9562

Girault, A.A. (1915) Australian Hymenoptera Chalcidoidea IV. Supplement. Memoirs of the Queensland Museum, 3, $180-299$.

Girault, A.A. (1922) New chalcid flies from eastern Australia (Hymenoptera, Chalcididae). II. Insecutor Inscitiae Menstruus, $10,100-108$.

Janzen, D.H., \& Hallwachs, W. (2011) Joining inventory by parataxonomists with DNA barcoding of a large complex tropical conserved wildland in northwestern Costa Rica. PLOS ONE, 6 (8), e18123. doi:10.1371/journal.pone.0018123

Jaikishan, Singh, R.S. \& Khan, M.A. (1997) A new genus and a new species of eulophine (Chalcidoidea: Eulophidae) from India. Shashpa, 4 (1), 9-11.

Koçak, A.Ö. \& Kemal, M. (2008) Nomenclatural notes on the genus group names in the order Hymenoptera (Chalcidoidea). Miscellaneous Papers, Centre for Entomological Studies, Ankara, No. 143, 3-7.

Narendran, T.C. (2011) Fauna of India, Eulophinae (Hymenoptera: Eulophidae). Zoological Survey of India, Kolkata, iii +442 pp.

Smith, M.A., Rodriguez, J.J., Whitfield, J.B., Deans, A.R., Janzen, D.H., Hallwachs, W. \& Hebert, P.D.N. (2008) Extreme diversity of tropical parasitoid wasps exposed by iterative integration of natural history, DNA barcoding, morphology, and collections. Proceedings of the National Academy of Sciences, 105, 12359-12364.

https://doi.org/10.1073/pnas.0805319105 